\title{
Improving patient outcomes: role of the primary care optometrist in the early diagnosis and management of age-related macular degeneration
}

This article was published in the following Dove Press journal:

Clinical Optometry

18 February 2013

Number of times this article has been viewed

Lei Liu

Mark Swanson

School of Optometry, University of Alabama at Birmingham, Birmingham, $\mathrm{AL}$, USA

Video abstract

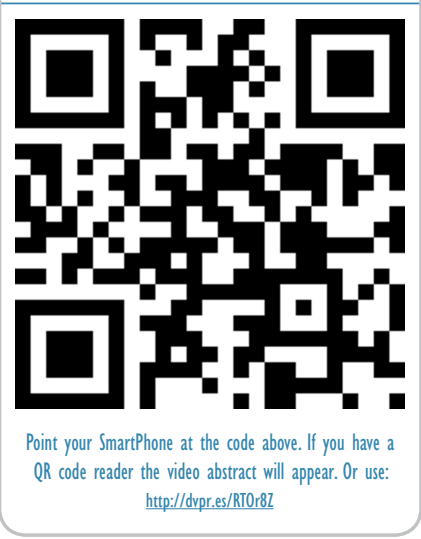

Correspondence: Lei Liu School of Optometry, University of Alabama at Birmingham, 1716 University Boulevard, Birmingham, AL 35294, USA

$\mathrm{Tel}+$ I 2059966627

Email liul7788@uab.edu
Abstract: Not long ago, the management of age-related macular degeneration (AMD) was confined to rehabilitating whatever vision had not been damaged by the disease. The recent successes of the anti-vascular endothelial growth factor agents and the antioxidant clinical trials have revolutionized AMD treatment. For the first time, there is realistic hope that the progression of AMD can be slowed down or stopped and near normal vision can be preserved. Developments in new vision tests, imaging modalities, and genetic testing have greatly improved the chance of detecting the onset of AMD and choroidal neovascularization. However, because the current treatments still cannot revive degenerated retinal cells, the best patient outcome that can be achieved is early detection of the disease and application of the appropriate treatment before too much retinal damage has occurred. The opportunities and challenges offered by the new treatment options and disease detection methods have redefined the role of primary care optometrists in AMD management. This review of literature and practice guidelines demonstrates that, in addition to the traditional roles of refraction and visual rehabilitation, the unique position of optometrists as the first-line eye-care providers has allowed them to play an important role in the early detection of AMD, patient education, lifestyle-change counseling, disease monitoring and referral, and nutrition supplement counseling. The active participation of primary care optometrists in the shared care of AMD management is likely to result in great improvement in patient outcomes. Optometrists also need to improve their competence in these areas to meet the new challenges. Although primary care optometrists have always managed patients with AMD, their role in managing this sight-threatening disease has not been adequately documented. In light of the recent game-changing developments in AMD treatment, it is important to review what primary care optometrists are doing, what they can do, and what they should do to improve patient outcomes in the new era of AMD management.

Keywords: detection, patient education, lifestyle-change counseling, disease monitoring, disease referral, nutrition supplement counseling

\section{Age-related macular degeneration}

Age-related macular degeneration (AMD) is an acquired degenerative disease of the macular area of the retina that, in its final stage, can cause severe visual impairment. AMD affects mainly older people and its prevalence increases with age. The prevalence of any AMD and late AMD (geographic atrophy [GA] or choroidal neovascularization [CNV]) in persons aged 40 years and older is between $5.2 \%$ and $14.3 \%$, and between $0.3 \%$ and $2.6 \%$, respectively, depending on race and ethnicity. ${ }^{1}$ AMD results in centrally located scotomas; reduced visual acuity, contrast sensitivity, color vision, and depth perception; and poor control of eye movements. AMD is one of the leading causes of severe visual impairment in 
developed countries. In the USA, AMD causes $54.4 \%$, $4.4 \%$, and $14.3 \%$ of legal blindness (acuity $<20 / 200$ ) and $22.9 \%, 3.2 \%$, and $14.1 \%$ of low vision (acuity $<6 / 12$ ) in white, black, and Hispanic persons, respectively. ${ }^{2}$ Globally, it is estimated that 32.9 million people suffer from AMDrelated visual impairments. ${ }^{3}$ Late AMD has debilitating effects on the patient's vision-related activities of daily living, such as reading, face recognition, and mobility, and negatively affects their quality of life, physical and mental well-being, and life expectancy. ${ }^{4}$ Further, AMD has enormous socioeconomic impacts on the society. In the USA, the annual Medicare payment for eye-related costs was US\$3390 per neovascular AMD patient. ${ }^{5}$ The annual cost of care for a bilateral neovascular AMD patient was $€ 12,250-39,348$ in Canada and Europe in 2005. 6 Globally, AMD-related annual direct and indirect costs were estimated to be $>$ US $\$ 500$ billion, and the disability-adjusted life year burden was 5,667,000. ${ }^{3}$

\section{Natural history and classification of AMD}

Normal aging results in morphological alterations of the retina and the retinal pigment epithelium (RPE), the formation of small drusen, and local hyper- or hypopigmentation. However, only a small percentage of older people's eyes have large drusen ( $\geq 125 \mathrm{~mm}$ ) and are at risk of one of the two forms of late AMD. The dry, atrophic form leads to complete degeneration of the RPE and associated photoreceptors but does not involve leakage of blood or serum into the retina. The wet, neovascular form involves CNV, serous or hemorrhagic detachment of the RPE, blood or serum leakage, and fibrovascular scarring in the retina. ${ }^{7}$

Several classification systems use stereo fundus images and trained readers to classify AMD based on the presence and severity of drusen, pigmentary changes, GA, and CNV. For optometric practice, the American Optometric Association (AOA) suggested a 4-stage AMD classification, based on the ophthalmoscopic appearance of the retina. ${ }^{8}$

1. Pigmentary abnormalities:

- RPE degeneration

- increased retinal pigment in the macular area.

2. Retinal pigment epithelial degeneration and increased retinal pigment:

- granules or clumps of gray or black pigment in or beneath the retina

- grayish-yellow or pinkish-yellow areas of varying density and configuration in the plane of the RPE.
3. Early AMD:

- soft, indistinct, or reticular drusen

- any type of drusen (except hard or indistinct) with RPE degeneration in the absence of signs of late AMD.

4. Late AMD:

- exudative AMD:

- RPE or serous detachment of the sensory retina

- subretinal or pigment epithelium hemorrhage.

- pure GA:

- GA in the absence of exudative macular degeneration

- loss of RPE and increased visualization of the underlying choroid.

Clinical features mentioned in the classification are shown in the fundus photographs in Figure 1. In the rest of this review, "early AMD" and "late AMD" refer to the stages of AMD defined in this classification.

\section{Risk factors}

Although the etiology of AMD is not completely understood, large numbers of risk factors have been reported. From the disease management point of view, risk factors are classified as either unmodifiable or modifiable.

\section{Unmodifiable factors}

There is strong and consistent evidence that increasing age, family history, obesity/high body mass index, and cataract surgery are associated with late AMD. ${ }^{9}$ Recent studies in the USA have shown that non-Hispanic whites have the highest prevalence rates of any AMD and late AMD compared with other racial/ethnic groups, while non-Hispanic blacks have the lowest rates. ${ }^{1}$ Multiple genes appear to be involved in the etiology of AMD. Initial genetic susceptibility, aging, and environmental factors may jointly determine the onset and phenotypes of AMD. ${ }^{10}$ Women may be at slightly higher risk of AMD, but the evidence is not conclusive. ${ }^{11}$ Darker (brown) eye colors appear to be associated with a slightly lower prevalence of AMD than eyes of lighter (blue or hazel) colors in people of the same race. ${ }^{12}$ There is inconsistent evidence that hyperopia and shorter axial length, hypertension, history of cardiovascular diseases, and diabetes are risk factors of wet AMD. ${ }^{9,13-16}$

\section{Modifiable factors}

Smoking is the strongest and most consistently found modifiable risk factor for late AMD. ${ }^{9}$ Current smokers have a higher incidence rate for late AMD than past smokers or those who 

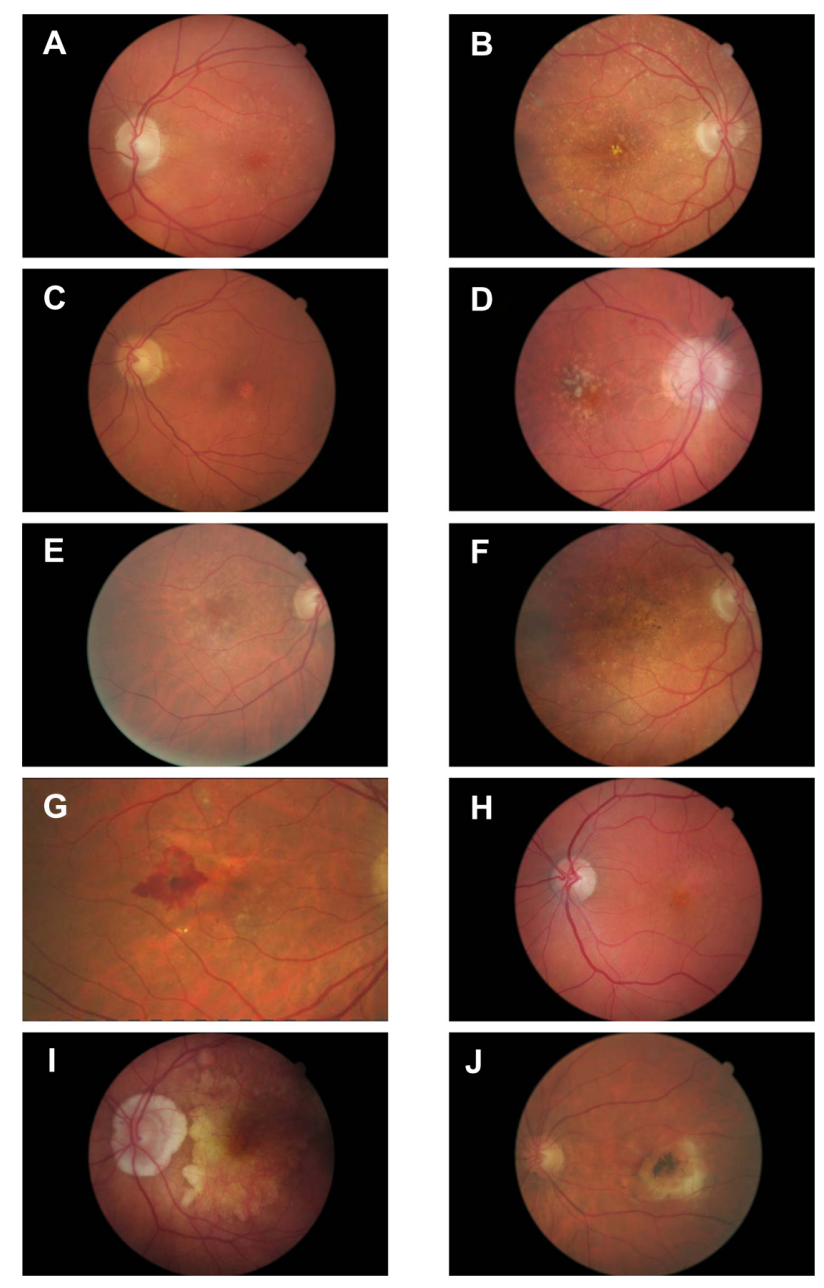

Figure I (A) Pigment hyperplasia and parafoveal retinal pigment epithelium (RPE) degeneration; (B) central confluent drusen with pigment hyperplasia; (C) RPE degeneration temporal to fovea; (D) large soft drusen with RPE hyperplasia; (E) large soft drusen; (F) drusen with RPE degeneration and hyperplasia; (G) wet age-related macular degeneration (AMD) with neovascular net; $(\mathbf{H})$ wet AMD with temporal serous detachment; (I) geographic atrophy; (J) end-stage wet AMD.

have never smoked. Late AMD occurs at a significantly earlier age in current smokers than in past smokers, and at an earlier age in past smokers than in those who have never smoked. ${ }^{17}$ There is no consistent evidence indicating that an increased risk of late or early AMD is associated with more exposure to the sun..$^{18}$ The recent European Eye Study (EUREYE) suggests that the damaging effects of phototoxicity become more pronounced only when antioxidants become insufficient. ${ }^{19}$ Less education and blue-collar occupation appear to be risk factors for early and/or late AMD but household income is not. ${ }^{20}$ Higher consumption of meat and dietary fat is a risk factor for early and/or late AMD while a healthy diet and more physical activity are associated with lower odds for early and wet AMD. ${ }^{21}$ More vigorous exercise (running) is associated with lower AMD risk. ${ }^{22}$

\section{New treatment options}

Strictly speaking, there is no cure for AMD, as no clinical therapy can yet revive degenerated retinal neural cells or RPE cells. However, recent developments have resulted in several treatment options that, when implemented in a timely manner, can effectively slow down or stop further degeneration of retinal neural or RPE cells, thus preventing severe vision loss.

\section{Treatment of wet AMD}

Laser photocoagulation and photodynamic therapy use a laser alone or a laser combined with a photosensitizer to destroy or close well-circumscribed new blood vessels. They have been shown to have limited effects in slowing down vision loss in a small portion of wet AMD cases and have several side effects. ${ }^{23,24}$

Anti-vascular endothelial growth factor (VEGF) treatment has rapidly become the first-line therapy for wet AMD. VEGFs are signaling proteins that stimulate blood vessel growth under oxidative stress and are believed to be mediators of intraocular neovascularization..$^{25}$ The Anti-VEGF Antibody for the Treatment of Predominantly Classic Choroidal Neovascularization in Age-Related Macular Degeneration (ANCHOR) Trial and the Minimally Classic/Occult Trial of the Anti-VEGF Antibody Ranibizumab in the Treatment of Neovascular Age-Related Macular Degeneration (MARINA) Trial showed that eyes with CNV treated with the VEGF antagonist ranibizumab have a five-letter increase in acuity on average, while untreated eyes decline by 20 letters. ${ }^{26}$ In a landmark clinical trial comparing the two major VEGF antagonists, ranibizumab and the much lower cost bevacizumab, the agents were shown to be clinically equivalent. ${ }^{27}$ Aflibercept was approved by the US Food and Drug Administration in November 2011. A number of newer agents targeting the same biological pathway are under development.

\section{Treatment of dry AMD}

The Age-Related Eye Disease Study (AREDS) tested the effectiveness of megadoses of antioxidants (vitamin A, 28,640 IU; vitamin C, $452 \mathrm{mg}$; and vitamin E, $400 \mathrm{IU}$ ) and/or minerals (zinc, $69.6 \mathrm{mg}$ and copper $1.6 \mathrm{mg}$ - the AREDS formula) in preventing AMD progression. It was found that alone or in combination, antioxidants and zinc reduced the risk of progression from intermediate AMD to late AMD by $\sim 20 \%$ and the risk of vision loss in advanced AMD by $10 \%{ }^{28}$ A second AREDS study, the AREDS2, currently ongoing, is testing the effectiveness of high doses of dietary supplemental 
xanthophylls (lutein and zeaxanthin) and omega-3 long-chain polyunsaturated fatty acids in preventing the development of advanced AMD and studying the effects of eliminating beta-carotene and/or reducing zinc dosage in the original AREDS formula. ${ }^{29}$ Early results suggest that dietary intake of lutein/zeaxanthin is inversely associated with the rates of late AMD and large or extensive intermediate drusen. ${ }^{30}$ Other smaller clinical trials have demonstrated the feasibility of using antioxidants, dietary xanthophylls, omega-3 fatty acids, and mineral supplements to treat dry AMD, increase macular pigment optical density (MPOD), and improve visual acuity. ${ }^{31}$ Possible side effects of using nutritional supplements to treat dry AMD include increased risk of lung cancer among smokers, increased risk of prostate cancer in men, increased mortality associated with beta-carotene intake, yellowish skin after taking very high doses of beta-carotene, and anemia with high doses of zinc and not enough copper. ${ }^{32}$ Lutein, zeaxanthin, omega-3 fatty acids, and vitamin $\mathrm{C}$ are considered safe. ${ }^{29}$ The potential benefits of vitamin therapies have largely been identified in studies of the US population. The generalizability of these results to other populations remains unknown. It should also be remembered that vitamin therapies for AMD are a public health intervention to reduce the burden of AMD at the population level. Within the AREDS trial, the absolute risk reduction for AMD advancement was a modest $6 \%$, which means that for every 17 persons with moderate AMD treated with the AREDS formula, one person will not develop late AMD who otherwise would.

\section{Prophylactic treatment}

A healthy diet that includes plenty of fatty cold water fish, vegetables, fruits, and nuts reduces the odds of late AMD. ${ }^{21}$ High blood plasma concentrations of lutein and zeaxanthin and high dietary intake of lutein/zeaxanthin are inversely associated with early, intermediate, and late AMD. ${ }^{31} \mathrm{~A}$ metaanalysis of AMD risks showed that time since smoking cessation had a significant protective impact in former smokers. ${ }^{17}$ A lifestyle that consists of a healthy diet, more exercise, and no smoking can result in a threefold reduction in the odds for early AMD development. ${ }^{21}$ However, a recent systematic review of clinical trials (not including AREDS2) suggested that taking vitamin $\mathrm{E}$ or beta-carotene supplements might not prevent the onset of AMD. ${ }^{33}$

\section{The importance of early detection}

Early detection of two events in the natural course of AMD - the onset of early AMD and then onset of wet AMD - holds the key for optimal patient outcome. The insidiousness of these events, however, presents opportunities and challenges to primary care optometrists. Detection of the onset of early AMD can motivate the patient to implement lifestyle changes to reduce the risk of late AMD. Although pathological changes associated with early AMD can interfere with the normal functioning of retinal neural cells, ${ }^{34}$ these changes are usually in the form of small-scale lesions randomly scattered in the macula. ${ }^{35}$ These lesions do not usually affect high-contrast visual acuity or impair one's ability to perform tasks of daily living, thus can easily elude the patient's attention. Therefore, detection is most likely to occur when the patient seeks help from eye-care professionals for reasons other than AMD - for example, for a new pair of spectacles.

The new treatments for wet AMD have a narrow time window of optimal effectiveness. Delays between detection and treatment are associated with more severe visual impairment. ${ }^{36}$ However, visual acuity in new CNV patients usually remains near normal until the fovea is involved. Fifty-six percent of the eyes with subfoveal CNV and $80 \%$ of the eyes with non-subfoveal CNV have acuities $\geq 20 / 40 .{ }^{37}$ Further, patients' knowledge of the disease is unreliable - a study reported that patients appeared not to recall an AMD diagnosis, even if it was made a year earlier. ${ }^{38}$ However, sight-threatening wet AMD develops rapidly. About $70 \%$ of new CNVs are extrafoveal and $56 \%$ are $<1$ disc area in size, having a relatively small impact on visual function. However, in 1-2 months, the CNV may double in size and become subfoveal, resulting in severe vision loss. ${ }^{39}$

Opportunistic screening for AMD within the community may not be effective. ${ }^{40}$ Visual acuity screening in the community has been judged to be no more effective than usual care in improving visual outcomes. ${ }^{41}$ There is evidence that telemedical referrals from optometrists to ophthalmologists, in the form of digital fundus photos or optical coherence tomography (OCT) scans, improve retinal disease management and reduce costs, ${ }^{42,43}$ but there has been no study on the effect of telemedical referrals of AMD patients by optometrists. At present, the preferred practice for detecting the onset of AMD and CNV is periodic in-office dilated fundus examination and at-home self-monitoring followed by confirmation by eye-care professionals. ${ }^{8,44}$

\section{Opportunities for primary care optometrists}

The new treatment options present great opportunities for primary care optometrists to play new roles in AMD management, 
in addition to the traditional roles of refraction and rehabilitation. Except for the acute phase of neovascularization, AMD generally shows slow progression. The predominant needs for AMD management are patient education, prevention, and risk reduction through counseling on lifestyle changes, provision of adequate optical aids, monitoring of the progression of the disease, and referral of wet AMD cases for treatment. Primary care optometrists can handle these tasks most effectively and efficiently. Shared care for chronic eye diseases among ophthalmology, optometry, and other eyecare professions does not only improve the patient's chance to maintain good functional vision and high quality of life but also reduces the stress on ophthalmology and increases cost-effectiveness of care. ${ }^{45-47}$

In countries where optometry is a licensed health care profession, optometrists are unquestionably the first-line eye-care professionals and the largest single eye-care workforce (Table 1).

The unique position of optometrists in eye-care delivery is adequately summarized by the AOA:

[O]ptometrists provide more than two-thirds of the primary eye care services in the United States. They are more widely distributed geographically than other eye care providers and are readily accessible for the delivery of eye and vision care services. ... Optometrists practice in more than 7,000 communities across the United States, serving as the sole primary eye care provider in more than 4,300 communities. $^{8}$

Due to the high prevalence of refractive errors and presbyopia, a large number of the older population needs spectacles. Only $\sim 27 \%$ of people aged 49 years or older are emmetropic. ${ }^{48}$ Only $2 \%$ of the 3654 participants of the Blue Mountains Eye Study (aged 49-97 years old) did not use any spectacles. ${ }^{48}$ Therefore, optometrists are most likely the first eye care professionals to be in contact and spend time with members of the population at risk for AMD.

Licensed optometrists have the didactic and clinical training, experience, and equipment to perform visual function measurements, fundus examination, retinal disease

Table I Numbers of optometrists and ophthalmologists

\begin{tabular}{lll}
\hline & Optometrists & Ophthalmologists \\
\hline USA & $34,200(2010)^{103}$ & $25,152^{*}(2012)^{104}$ \\
UK & $10,482(2011)^{105}$ & $3200 *(2012)^{104}$ \\
Australia & $3066(2006)^{106}$ & $895(2012)^{104}$ \\
Canada & $4581(2009)^{107}$ & $1137(2012)^{104}$ \\
\hline
\end{tabular}

Note: *Number significantly higher than reported from other sources. recognition, and refraction, which are the key components in AMD detection and management. For example, while only $4 \%$ of the general practitioners in a UK study of referrals to a hospital eye department commented on the fundus and used ophthalmoscopy, $94 \%$ of the optometrists used ophthalmoscope to examine the fundus. ${ }^{49}$ The 2008 AOA Scope of Practice Survey revealed that $91.5 \%$ of the $\sim 1000$ optometrists surveyed managed or co-managed patients with macular degeneration. ${ }^{50}$

\section{What optometrists can do to improve patient outcome in AMD management Identification of high-risk patients and detection of early AMD}

\section{Patient history}

Although the patient's self-reported AMD history is unreliable, ${ }^{38,51}$ an inquiry of patient history that includes known AMD risk factors will help to identify high-risk patients. Adults $\geq 55$ years and having two or more of the AMD risk factors should be followed-up annually. ${ }^{8}$ In combination with genetic tests, this can greatly improve the accuracy of predicting the patient's risk of developing AMD.

\section{Genetic tests}

Probes for hemorrhagic AMD-susceptible genes are becoming commercially available. These tests typically involve the collection of a buccal swab followed by laboratory evaluation. Tests for six variants in five genes related to AMD, combined with AMD risk factors such as age, sex, education, smoking and body mass index, can predict progression to later AMD with a high accuracy. ${ }^{52}$ The American Academy of Ophthalmology has not yet recommended routine use of genetic testing except in "patients with clinical findings suggestive of a Mendelian disorder whose causative gene(s) have been identified." 53 Optometrists should learn the language of genetic testing, understand its potential in AMD management, and be prepared to work with trained genetic counselors.

\section{Visual function tests}

The standard high-contrast distance visual acuity is unlikely to detect AMD in its early stage. However, there have been many studies showing that early AMD patients with normal acuity may exhibit deficiencies in other vision tests. Compared with age-matched normal controls, early AMD patients have poorer low-luminance/low-contrast visual acuity, slowed 
word-reading rate, loss of contrast sensitivity in the mid- to high spatial frequency range, tritan color vision defects, slowed dark adaptation, slowed recovery after exposure to a glare source, and loss of sensitivity to light flicker. ${ }^{54,55}$

More recently, Dimitrov and colleagues showed that while rod dark-adaptation rate had a better sensitivity (87\%), a more clinically deployable combination of $14 \mathrm{~Hz}$ flicker threshold and photo-stress dynamic could detect $71 \%$ of early AMD cases and took 10-28 minutes. ${ }^{56}$ De Kinkelder and colleagues found that early AMD subjects had a significantly lower hit rate than healthy controls in a rarebit test (detecting one or two very small light spots). ${ }^{57}$ Wang and colleagues demonstrated that the ability to detect small bumps on an otherwise circular stimulus (shape discrimination) was significantly reduced in eyes with early AMD. ${ }^{58}$ Bedell and colleagues found that early AMD subjects had more difficulties in detecting orientation disturbance in a patch of small line segments (line-segment orientation test). ${ }^{59}$ Liu and White found that while early AMD subjects could discriminate two intact textures with great accuracy based on their structural difference, that ability dropped off much more quickly than in normal controls when the textures were systematically degraded by random texture-check deletion (degraded-texture discrimination test). ${ }^{35}$

One challenge in primary care AMD detection is to develop "non-standard, yet clinically-practical" vision tests. ${ }^{55}$ Some of the tests mentioned require dedicated equipment or are long and arduous, thus may not fit in a busy office schedule. Another concern is test specificity. Detection of early AMD requires differentiating AMD suspects from normal older persons. Some of the threshold tests mentioned are known to be sensitive to age-related yellowing of the lens, mild cataract, and miosis. The procedures to discount the pre-retinal influences in these tests can be difficult, thus may restrict their use in primary care. Suprathreshold tests are less affected by pre-retinal factors, thus can be conducted more easily in clinics at lower cost. Finally, even if an observed deficit is known to be retinal in origin, it may not be the result of AMD. It is well known that many of these tests are also sensitive to retinal diseases such as diabetic retinopathy. A more specific diagnosis of AMD requires fundus examination.

\section{Ocular examination}

The benefits of dilated fundus examination are well documented in the detection of diabetic retinopathy. Un-dilated fundus examination - even by retina specialists - shows a high rate of missed diabetic retinopathy findings. ${ }^{60}$ While there is no direct evidence that the detection of AMD is aided by fundus examination with dilated pupil, practice guidelines of optometric associations, such as the AOA, clearly suggest dilated examination as a routine procedure in caring for patients at risk of AMD. ${ }^{8}$ In a few available surveys, the percentage of optometrists using dilated fundus examination in AMD management ranged from $20 \%$ to $86 \%{ }^{61,62}$

\section{New imaging modalities}

Abnormal distribution of MPOD may serve as an early predictor of AMD risk. ${ }^{63}$ The most popular, least invasive, and least expensive MPOD measurement is heterochromatic flicker photometry (HFP), ${ }^{63}$ which is based on the patient's ability to perceive flicker from alternating blue and green lights (strongly and weakly absorbed by macular pigments, respectively). Typically, one blue light threshold intensity at fixation (foveal center) and another at a peripheral retinal location are measured, and the ratio of the foveal and peripheral blue light threshold intensities is the measurement of MPOD. Desktop devices based on HFP are commercially available. AOA practice strategies suggest that MPOD measurement may be useful in identifying patients who are at risk for AMD. ${ }^{64}$ Because HFP is a subjective measurement, the task can be conceptually difficult to some patients and the patient's training and attention during testing may have a significant impact on the outcome. ${ }^{63}$

Fundus autofluorescence (FAF) imaging is a noninvasive procedure that allows topographic mapping of the lipofuscin distribution in the RPE cell monolayer. Recent technical developments have made it possible to use a set of excitation and barrier filters to take FAF images with a fundus camera. ${ }^{65}$ The association between excessive accumulation of lipofuscin and AMD has made FAF a new imaging modality for early AMD detection. ${ }^{66}$

\section{Management of wet AMD}

The full benefit of the anti-VEGF treatment can be best realized when $\mathrm{CNV}$ is detected early. Unlike detecting early AMD, detecting the onset of wet AMD requires identifying signs of CNV among patients with dry AMD, so different methods and management strategies are needed.

\section{In-office examinations}

CNV can be reliably detected using stereoscopic biomicroscopy, fundus photography, fluorescein angiography, and OCT scanning in eye care professionals' offices. These techniques are not considered exclusive; rather, they complement each other. While fluorescein angiography is still the gold 
standard for the diagnosis of CNV, OCT has rapidly become accepted as a necessary tool in AMD management. It has been shown that OCT is equal to or more sensitive than fluorescein angiography in detecting $\mathrm{CNV}^{67}$ Some optometrists have started to use OCT in managing AMD. ${ }^{62,68}$ The American Academy of Ophthalmology recommends a 6- to 24-month interval for in-office examination for asymptomatic patients with early AMD, dry AMD, and large drusen or wet AMD in one eye. ${ }^{44}$ The AOA recommends stereo fundus biomicroscopy with pupillary dilation at a 6- to 12-month interval for patients with early AMD or dry AMD and at a 4- to 6-month interval for patients with soft confluent drusen and granular pigmentary degeneration, plus fundus photography at a 1 - to 2-year interval. ${ }^{8}$

\section{At-home self-monitoring}

Even the periodic in-office evaluations by eye care professionals may not always capture CNV early enough. Of wet AMD patients referred to retinal clinics, $80 \%$ had large and subfoveal CNV and only $20 \%$ had $>20 / 40$ acuity, ${ }^{69}$ indicating that the CNVs were diagnosed $>5$ months after onset. ${ }^{70}$ To detect CNV within the optimal treatment window, daily self-monitoring of the central visual field is recommended as an adjunct to periodic examinations. ${ }^{44}$ The recommended instrument is the Amsler grid. ${ }^{8,44}$ While the Amsler grid is designed to capture perceived spatial distortion (metamorphopsia) caused by $\mathrm{CNV}$, its sensitivity is poor. ${ }^{71} \mathrm{New}$ instruments are being developed to improve the sensitivity of self-monitoring. Preferential hyperacuity perimetry (PHP) uses a dotted rather than solid line to reduce stimulus redundancy and presents physical distortions in the line to compete with the perceptual distortions caused by metamorphopsia. ${ }^{72}$ In-office PHP testing correctly identified 53 of 65 eyes with $\mathrm{CNV}$, but also incorrectly identified seven of 57 eyes without $\mathrm{CNV}^{73}$ A home monitoring version of PHP is now available. ${ }^{74}$ Other suprathreshold vision tests that have the potential to detect CNV-related metamorphopsia include the shape discrimination, line-segment orientation, and degraded-texture discrimination tests. Fluid in the retina and small scotomas associated with $\mathrm{CNV}$ may result in detectable deficits in near acuity, reading rate, blue-yellow color vision, recovery from glare, dark adaptation, and flicker sensitivity. ${ }^{54}$ Clinical trials on these tests may help to select the more sensitive instruments for self-monitoring. At present, the AOA recommends the Amsler grid test every other day for patients with $\mathrm{CNV}$ risk and the patient should return to an eye care professional for further examination within 24 hours of the onset of new symptoms. ${ }^{8}$

\section{Referral to a retinal specialist}

Timely referral of a CNV patient to a retina specialist for treatment is vitally important to patient outcome. There have been clearly defined procedural guidelines to expedite referral of wet AMD suspects to retinal specialists for treatment. The recommendations are an immediate referral when $\mathrm{CNV}$ is suspected in the USA and an urgent referral for symptoms indicative of $\mathrm{CNV}$ within 1 week in the UK. ${ }^{8,75}$

The quality of the referral made by an optometrist has a direct impact on the patient's receiving timely treatment and on the effectiveness of the secondary care, but quantitative assessments of optometrist referral quality are scarce. A UK study found a low referral accuracy of $37 \%{ }^{76}$ Another UK study found that among patients referred by community optometrists to a macular assessment clinic, $63 \%$ had wet AMD and 18\% had RPE detachment. ${ }^{61}$ Other studies also found high-quality referrals from community optometrists. ${ }^{77,78}$ There is a need for more studies of optometrist referral pattern and quality in different eye-care delivery systems.

\section{Follow-up after treatment}

The treatment benefit of anti-VEGF agents is not permanent for all patients. In a large portion of patients, recurrent leakage and further vision loss may occur, and the treatment may need to "continue indefinitely." 27 To improve safety and to reduce the cumulative financial burden of wet AMD treatment, an as-needed dosing regimen is needed. Recent clinical trials have demonstrated the feasibility of a retreatment scheme based on acuity loss, presence of fluid in OCT scan, hemorrhage, or dye leakage on fluorescein angiography. ${ }^{27,79}$ The majority of the retreatment decisions appeared to be made based on OCT finding alone or OCT plus fundus examination and visual function. ${ }^{80}$ This is a fast developing area. There are no established practice guidelines and optometrists' roles are not clearly defined.

\section{Management of dry AMD}

Only a small percentage of dry AMD cases convert to wet. Under some eye care models, dry AMD is managed in the community by optometrists until wet AMD is detected. ${ }^{61}$ The AOA recommend a follow-up evaluation every 4-12 months, which includes visual function tests, stereo fundus biomicroscopy, central 10-degree automated visual field and fundus photography. Patients should be advised to use the Amsler grid or other self-monitoring devices regularly at home and to seek professional help immediately if new symptoms occur. The management also includes patient education, recommendation of ultraviolet (UV) protection, 
counseling on lifestyle changes (smoking cessation, healthy diet, and exercise), and recommendation of antioxidant supplementation.

\section{Patient education and increasing AMD awareness}

Despite its devastating consequences, AMD is not a disease that is well known to the public. When asked "How familiar are you with the medical condition known as age-related macular degeneration or AMD?," 4\%-30\% of respondents from 14 countries considered themselves familiar with the disease. ${ }^{81}$ A Canadian survey showed that only $20.2 \%$ of the respondents were familiar with AMD as a cause of vision loss and few knew the risk factors. ${ }^{82}$ The detection of the signs of any AMD is thus an appropriate opportunity for the optometrist, who is likely the first and only eye care professional the patient has seen, to educate the patient about the sight-threatening nature of AMD, the risk factors, and the treatment options. For the patient, finding that they have signs of AMD is also a strong motivation to take actions such as stopping smoking, taking nutrition supplements, and exercising more. For example, a study reported that blindness evoked the same fear as, or more fear than, lung cancer, heart disease, and stroke, and a large number of smokers would be highly motivated to quit smoking if they knew they would develop early signs of blindness. ${ }^{83}$

\section{Smoking cessation counseling}

It has been reported that only $5 \%-32 \%$ of the general public believe that smoking is a cause of blindness. ${ }^{81}$ A study of tobacco counseling efficacy showed that receiving advice from any health care professional increased quit rates. ${ }^{84}$ Although the study did not include optometrists, optometrists are in an authoritative position to counsel their patients not to start smoking or to quit smoking. It has been found that optometrists are well aware of the negative impacts of smoking on ocular health and would like to advise their patients on smoking cessation, but only a small number of them routinely ask about their patients' smoking habits. ${ }^{85-87}$ Studies found that some considered smoking cessation counseling inconsistent with their role as optometrists and were afraid that their patients might feel smoking cessation was outside the scope of optometry practice; lack of time, training, patient material, knowledge on smoking cessation drugs and resources, patient motivation, and financial incentives were among the other barriers identified. ${ }^{86-88}$ Optometry students and practicing optometrists have been reported as feeling that they do not possess knowledge about tobacco use, dependence, or the skills to advise patients on cessation. ${ }^{89}$ This is likely to change rapidly in the USA. New quality-of-care guidelines have mandated smoking cessation counseling by health care providers, including optometrists, for adults enrolled in the major federal health care program in the USA. ${ }^{90}$ Sheck and colleagues have offered a simple $\mathrm{ABC}$ smoking cessation method to busy optometrists: "Ask (do you smoke?), Brief advice (short, $30 \mathrm{sec}$ advice on the eye health benefit for completely stopping smoking) and Cessation treatment (refer the patient to cessation service or general medical practitioner). ${ }^{91}$ Considering the larger safety margin that those who have never smoked have over past smokers in terms of AMD risk, tobacco use counseling should be extended to all adults.

\section{Nutrition counseling}

Nutrition counseling consists of advice on healthy diet and nutrition supplementation. Optometrists should inquire about dietary habits in all patients aged 55 years or older, with or without a diagnosis of AMD, and should give advice on the importance of a healthy diet on eye health. A healthy diet should include red, orange, and dark green leafy vegetables, fruits, nuts, low fat milk, whole grains, fish, beans, and small portions of poultry and lean meat. ${ }^{92}$ Concise nutrition counsel can be provided "in a matter of minutes," and should convey the following information to patients in a clear and direct manner: that a healthy diet can result in reduced AMD risk and other eye health benefits, the constituents of a healthy diet, the nutrients that may help to prevent or delay AMD, and the food and quantity of food that should be consumed. ${ }^{93,94}$ Patients should be given specific examples of the types of foods that contain the necessary nutrients - for example, "Dark green vegetables such as kale, spinach, and broccoli are especially good sources of lutein and zeaxanthin" - so that they know what to purchase. ${ }^{64}$ However, "there is insufficient evidence in the literature to recommend routine nutritional supplementation in healthy adults for primary prevention of AMD." ${ }^{95}$

For patients with a diagnosis of intermediate or late AMD, the amount of antioxidants and minerals from even a healthy diet will not be sufficient to slow down AMD progression and preserve vision. ${ }^{96}$ The recommended dietary allowances of beta-carotene, vitamin $\mathrm{E}$, vitamin $\mathrm{C}$, and zinc for adult males are only one-nineteenth, one-eighteenth, one-fifth, and one-sixth respectively, of the dosages in the AREDS formula (available at http://iom.edu/Activities/ Nutrition/SummaryDRIs/ /media/Files/Activity\%20Files/ Nutrition/DRIs/RDA\%20and\%20AIs_Vitamin\%20and\%20 Elements.pdf). 
It is recommended that "patients with intermediate risk of AMD or advanced AMD in one eye should consider taking AREDS-type supplements." Although the therapeutic advantage of nutrition supplements may outweigh their side effects, optometrists should consider the known contraindications and adverse reactions when advising AMD patients on taking nutritional supplements. ${ }^{32}$ Women and obese individuals may need higher doses of lutein and zeaxanthin than men and thinner individuals because some of the nutrients may end up in fat tissue. ${ }^{97}$

Optometrists are providing nutrition counseling. About $50 \%$ of the respondents to the 2008 AOA Scope of Practice Survey wrote orders of vitamin therapy for patients. ${ }^{50}$ Surveys in the USA and UK have shown that the majority of optometrists provide nutrition counseling, recommend antioxidant supplements, and distribute nutrition information materials to AMD patients. ${ }^{62,98}$

\section{UV protection}

Among people who were familiar with AMD, only $32 \%$ were aware of the link between unprotected exposure to sunlight and AMD. ${ }^{81}$ Although the evidence is inconsistent concerning the association between AMD and lifetime sunlight/UV exposure or the increased post-surgery UV exposure after cataract surgery, the cost of protecting the eyes from excessive exposure to sunlight and UV is so low that optometrists are advised to recommend UV protection to all patients. ${ }^{8,99}$ Yellow-tinted filters reduce blue light and may have the effect of improving contrast. However, blocking blue light may interrupt the circadian cycle and may reduce scotopic visual sensitivity. ${ }^{100}$ Optometrists should consider the patient's indoor and outdoor needs and difficulties in the dark when prescribing UV protection. A pair of wraparound sunglasses blocks UV light scattered from the side of the lenses and thus offers better protection. ${ }^{101} \mathrm{~A}$ wide-brimmed hat can reduce $\sim 50 \%$ of $U V$ radiation.

In counseling patients to alter modifiable risk factors of AMD, optometrists should direct patients to organizations and practitioners who are specialized in smoking cessation, nutrition, and exercise. Optometrists should also be ready to provide materials that contain facts, guidance, and resources. Professional organizations, such as the AOA, have patient education materials in print or online to aid optometrists in nutrition counseling. ${ }^{102}$

\section{Conclusion}

The new AMD treatment options present new opportunities for primary care optometrists to be engaged in all phases of AMD management, rather than just traditional vision rehabilitation. Much of the debate about the role of optometrists in AMD detection, diagnosis, and referral is not about whether optometrists should do these jobs but about the quality of these jobs. It is thus a challenge to the schools and colleges of optometry and optometric associations to enhance didactic instruction, clinical teaching, and continuing education on AMD and retinal disease management and to provide up-to-date practice guidelines. It is a challenge to optometrists themselves to increase their knowledge and competence in AMD therapies, detection methods, genetic testing, and new retinal imaging techniques. It is a challenge to researchers to develop clinically practical vision tests and imaging modalities and to document and analyze primary care optometrists' contributions in improving patient outcome in AMD management.

\section{Disclosure}

The authors declare no conflicts of interest in this work.

\section{References}

1. Klein R, Chou CF, Klein BE, Zhang X, Meuer SM, Saaddine JB Prevalence of age-related macular degeneration in the US population. Arch Ophthalmol. 2011;129(1):75-80.

2. Congdon N, O'Colmain B, Klaver CC, et al; Eye Diseases Prevalence Research Group. Causes and prevalence of visual impairment among adults in the United States. Arch Ophthalmol. 2004;122(4):477-485.

3. Access Economics. The Global Economic Cost of Visual Impairment. Canberra, Sydney, and Melborne: Access Economics; 2010. Available from: http://www.amdalliance.org/user_files/documents/Global\%20 cost\%20of\%20VI_FINAL\%20report.pdf. Accessed August 29, 2012.

4. Alliance for Aging Research. The Silver Book: Vision Loss. Washington, DC: Alliance for Aging Research; 2012.

5. Day S, Acquah K, Lee PP, Mruthyunjaya P, Sloan FA. Medicare costs for neovascular age-related macular degeneration,1994-2007. Am J Ophthalmol. 2011;152(6):1014-1020.

6. Cruess AF, Zlateva G, Xu X, et al. Economic burden of bilateral neovascular age-related macular degeneration: multi-country observational study. Pharmacoeconomics. 2008;26(1):57-73.

7. Fine SL, Berger JW, Maguire MG, Ho AC. Age-related macular degeneration. N Engl J Med. 2000;342(7):483-492.

8. American Optometric Association. Care of the Patient with Age-Related Macular Degeneration: Reference Guide for Clinicians. Optometric Clinical Practice Guideline. St Louis, MO: American Optometric Association; 2004. Available from: http://www.aoa.org/documents/ CPG-6.pdf. Accessed October 25, 2012.

9. Chakravarthy U, Wong TY, Fletcher A, et al. Clinical risk factors for age-related macular degeneration: a systematic review and metaanalysis. BMC Ophthalmol. 2010;10:31.

10. Swaroop A, Chew EY, Rickman CB, Abecasis GR. Unraveling a multifactorial late-onset disease: from genetic susceptibility to disease mechanisms for age-related macular degeneration. Annu Rev Genomics Hum Genet. 2009;10:19-43.

11. Chakravarthy U, Augood C, Bentham GC, et al. Cigarette smoking and age-related macular degeneration in the EUREYE Study. Ophthalmology. 2007;114(6):1157-1163.

12. Tomany SC, Klein R, Klein BE; Beaver Dam Eye Study. The relationship between iris color, hair color, and skin sun sensitivity and the 10-year incidence of age-related maculopathy: the Beaver Dam Eye Study. Ophthalmology. 2003;110(8):1526-1533. 
13. Lavanya R, Kawasaki R, Tay WT, et al. Hyperopic refractive error and shorter axial length are associated with age-related macular degeneration: the Singapore Malay Eye Study Invest Ophthalmol Vis Sci. 2010;51(12):6247-6252.

14. Liu C, Maguire M, Ying GS; CAPT Research Group. Refractive error in the Complications of Age-Related Macular Degeneration Prevention Trial (CAPT): risk of late AMD and 5-year changes. Invest Ophthalmol Vis Sci. 2007;48:E-Abstract 2090.

15. Hogg RE, Woodside JV, Gilchrist SE, et al. Cardiovascular disease and hypertension are strong risk factors for choroidal neovascularization. Ophthalmology. 2008;115(6):1046-1052. e2.

16. Topouzis F, Anastasopoulos E, Augood C, et al. Association of diabetes with age-related macular degeneration in the EUREYE study. $\mathrm{Br} J$ Ophthalmol. 2009;93(8):1037-1041.

17. Neuner B, Komm A, Wellmann J, et al. Smoking history and the incidence of age-related macular degeneration - results from the Muenster Aging and Retina Study (MARS) cohort and systematic review and meta-analysis of observational longitudinal studies. Addict Behav. 2009;34(11):938-947.

18. Cruickshanks KJ, Klein R, Klein BE, Nondahl DM. Sunlight and the 5-year incidence of early age-related maculopathy: the beaver dam eye study. Arch Ophthalmol. 2001;119(2):246-250.

19. Fletcher AE, Bentham GC, Agnew M, et al. Sunlight exposure, antioxidants, and age-related macular degeneration. Arch Ophthalmol. 2008;126(10):1396-1403.

20. Jia L, Shen X, Fan R, et al. Risk factors for age-related macular degeneration in elderly Chinese population in Shenyang of China. Biomed Environ Sci. 2011;24(5):506-511.

21. Mares JA, Voland RP, Sondel SA, et al. Healthy lifestyles related to subsequent prevalence of age-related macular degeneration. Arch Ophthalmol. 2011;129(4):470-480.

22. Williams PT. Prospective study of incident age-related macular degeneration in relation to vigorous physical activity during a 7-year follow-up. Invest Ophthalmol Vis Sci. 2009;50(1):101-106.

23. Laser photocoagulation for juxtafoveal choroidal neovascularization. Five-year results from randomized clinical trials. Macular Photocoagulation Study Group. Arch Ophthalmol. 1994;112(4):500-509.

24. Wormald R, Evans J, Smeeth L, Henshaw K. Photodynamic therapy for neovascular age-related macular degeneration. Cochrane Database Syst Rev. 2007;3:CD002030.

25. Schlingemann RO, Witmer AN. Treatment of retinal diseases with VEGF antagonists. Prog Brain Res. 2009;175:253-267.

26. Mitchell P, Korobelnik JF, Lanzetta P, et al. Ranibizumab (Lucentis) in neovascular age-related macular degeneration: evidence from clinical trials. Br J Ophthalmol. 2010;94(1):2-13.

27. Martin DF, Maguire MG, Fine SL, et al; Comparison of Age-Related Macular Degeneration Treatments Trials (CATT) Research Group. Ranibizumab and bevacizumab for treatment of neovascular agerelated macular degeneration: two-year results. Ophthalmology. 2012;119(7):1388-1398.

28. Age-Related Eye Disease Study Research Group. A randomized, placebo-controlled, clinical trial of high-dose supplementation with vitamins $\mathrm{C}$ and $\mathrm{E}$, beta carotene, and zinc for age-related macular degeneration and vision loss: AREDS report no 8. Arch Ophthalmol. 2001;119(10):1417-1436.

29. Age-Related Eye Disease Study Research Group. Age-Related Eye Disease Study 2 Protocol: Age-Related Eye Disease Study 2 (AREDS2): Available from: https://web.emmes.com/study/areds2/resources/ areds2_protocol.pdf. Accessed August 2, 2012.

30. SanGiovanni JP, Chew EY, Clemons TE, et al; Age-Related Eye Disease Study Research Group. The relationship of dietary carotenoid and vitamin A, E, and C intake with age-related macular degeneration in a case-control study: AREDS Report no 22. Arch Ophthalmol. 2007;125(9):1225-1232.

31. Ma L, Dou HL, Wu YQ, et al. Lutein and zeaxanthin intake and the risk of age-related macular degeneration: a systematic review and meta-analysis. Br J Nutr. 2012;107(3):350-359.
32. Bartlett H, Eperjesi F. Possible contraindications and adverse reactions associated with the use of ocular nutritional supplements. Ophthalmic Physiol Opt. 2005;25(3):179-194.

33. Evans JR, Lawrenson JG. Antioxidant vitamin and mineral supplements for preventing age-related macular degeneration. Cochrane Database Syst Rev. 2012;6:CD000253.

34. Johnson PT, Lewis GP, Talaga KC, et al. Drusen-associated degeneration in the retina. Invest Ophthalmol Vis Sci. 2003;44(10):4481-4488.

35. Liu L, White J. Early age-related macular degeneration impairs tolerance to stimulus degradation. Optom Vis Sci. 2010;87(8): 532-542.

36. Arias L, Armadá F, Donate J, et al. Delay in treating age-related macular degeneration in Spain is associated with progressive vision loss. Eye (Lond). 2009;23(2):326-333.

37. Complications of Age-Related Macular Degeneration Prevention Trial Research Group. Laser treatment in patients with bilateral large drusen: the complications of age-related macular degeneration prevention trial. Ophthalmology. 2006;113(11):1974-1986.

38. Patty L, Wu C, Torres M, Azen S, Varma R; Los Angeles Latino Eye Study Group. Validity of Self-reported Eye Disease and Treatment in a Population-based Study: The Los Angeles Latino Eye Study. Ophthalmology. 2012;119(9):1725-1730.

39. Pauleikhoff D. Neovascular age-related macular degeneration: Natural History and Treatment Outcomes. Retina. 2005;25(8):1065-1084.

40. Smeeth L, Iliffe S. Community screening for visual impairment in the elderly. Cochrane Database Syst Rev. 2006;3:CD001054.

41. Chou R, Dana T, Bougatsos C. Screening older adults for impaired visual acuity: a review of the evidence for the US Preventive Services Task Force. Ann Intern Med. 2009;151(1):44-58, W11-20.

42. Hanson C, Tennant MT, Rudnisky CJ. Optometric referrals to retina specialists: evaluation and triage via teleophthalmology. Telemed $J E$ Heath. 2008;14(5):441-445.

43. Kelly SP, Wallwork I, Haider D, Qureshi K. Teleophthalmology with optical coherence tomography imaging in community optometry. Evaluation of a quality improvement for macular patients. Clin Ophthalmol. 2011;5:1673-1678.

44. American Academy of Ophthalmology Retina Panel. Preferred Practice Guidelines ${ }^{\circledR}$. Age-Related Macular Degeneration. San Francisco, CA: American Academy of Ophthalmology; 2008. Available from: http:// one.aao.org/asset.axd?id=b1f95ead-7fd4-49e7-bcc9-b12249916069. Accessed October 26, 2012.

45. Myers RI. Interprofessional strategies for optometry and ophthalmology in the future. Optom Vis Sci. 1995;72(1):42-44.

46. Banes MJ, Culham LE, Bunce C, Xing W, Viswanathan A, GarwayHeath D. Agreement between optometrists and ophthalmologists on clinical management decisions for patients with glaucoma. $\mathrm{Br} J$ Ophthalmol. 2006;90(5):579-585.

47. O’Connor PM, Harper CA, Brunton CL, Clews SJ, Haymes SA, Keeffe JE. Shared care for chronic eye diseases: perspectives of ophthalmologists, optometrists and patients. Med J Aust. 2012;196(10): 646-650.

48. Attebo K, Ivers RQ, Mitchell P. Refractive errors in an older population: the Blue Mountains Eye Study. Ophthalmology. 1999;106(6): 1066-1072.

49. Davey CJ, Green C, Elliott DB. Assessment of referrals to the hospital eye service by optometrists and GPs in Bradford and Airedale. Ophthalmic Physiol Opt. 2011;31(1):23-28.

50. Edlow RC, Marcus GR. Highlights: 2008 American Optometric Association Scope of Practice Survey. Optometry. 2009;80(5):267-270.

51. Goujon N, Brown CM, Xie J, et al. Self-reported vision and health of indigenous Australians. Clin Experiment Ophthalmol. 2010;38(8): 796-804.

52. Seddon JM, Reynolds R, Maller J, Fagerness JA, Daly MJ, Rosner B. Prediction model for prevalence and incidence of advanced age-related macular degeneration based on genetic, demographic, and environmental variables. Invest Ophthalmol Vis Sci. 2009;50(5):2044-2053.

53. Stone EM, Aldave AJ, Drack AV, et al. Recommendations for Genetic Testing of Inherited Eye Diseases: Report of the American Academy of Ophthalmology Task Force on Genetic Testing. Ophthalmology. Nov 2012;119(11):2408-2410. 
54. Hogg RE, Chakravarthy U. Visual function and dysfunction in early and late age-related maculopathy. Prog Retin Eye Res. 2006;25(3): 249-276.

55. Lovie-Kitchin J, Feigl B. Assessment of age-related maculopathy using subjective vision tests. Clin Exp Optom. 2005;88(5):292-303.

56. Dimitrov PN, Robman LD, Varsamidis M, et al. Visual function tests as potential biomarkers in age-related macular degeneration. Invest Ophthalmol Vis Sci. 2011;52(13):9457-9469.

57. de Kinkelder R, van Leeuwen TG, Verbraak FD. Detection of earlystage age related macular degeneration with a compact rarebit test. $\mathrm{Br}$ J Ophthalmol. 2012;96(10):1354-1355.

58. Wang YZ, Wilson E, Locke KG, Edwards AO. Shape discrimination in age-related macular degeneration. Invest Ophthalmol Vis Sci. 2002;43(6):2055-2062.

59. Bedell HE, Tong J, Woo SY, House JR, Nguyen T. Orientation discrimination with macular changes associated with early AMD. Optom Vis Sci. 2009;86(5):485-491.

60. Harding SP, Broadbent DM, Neoh C, White MC, Vora J. Sensitivity and specificity of photography and direct ophthalmoscopy in screening for sight threatening eye disease: the Liverpool Diabetic Eye Study BMJ. 1995;311(7013):1131-1135.

61. Creer R, Parkes J, Charles S, Harper R. Optometric management of age-related macular degeneration: referral and referral refinement pilot surveys. Optometry in Practice. 2010;11(1):13-25.

62. Loughman J. Online AMD research study for optometrists: current practice in the Republic of Ireland and UK. Optometry in Practice. 2011;12(4):135-144.

63. Bernstein PS, Delori FC, Richer S, van Kuijk FJ, Wenzel AJ. The value of measurement of macular carotenoid pigment optical densities and distributions in age-related macular degeneration and other retinal disorders. Vision Res. 2010;50(7):716-728.

64. Nutrition counseling in the optometric practice. Optometry. 2009;80(10): $587-589$

65. Spaide RF. Autofluorescence imaging with the fundus camera. In: Holz FG, Schmitz-Valckenberg S, Spaide RF, Bird AC, editors. Atlas of Fundus Autofluorescence Imaging. Berlin and Heidelberg: Springer; 2007:49-53.

66. Schmitz-Valckenberg S, Fleckenstein M, Scholl HP, Holz FG. Fundus autofluorescence and progression of age-related macular degeneration Surv Ophthalmol. 2009;54(1):96-117.

67. Padnick-Silver L, Weinberg AB, Lafranco FP, Macsai MS. Pilot study for the detection of early exudative age-related macular degeneration with optical coherence tomography. Retina. 2012;32(6): 1045-1056.

68. Whatham AR, Pye D. Imaging into the future of optometric practice Clin Exp Optom. 2008;91(6):501-503.

69. Olsen TW, Feng X, Kasper TJ, Rath PP, Steuer ER. Fluorescein angiographic lesion type frequency in neovascular age-related macular degeneration. Ophthalmology. 2004;111(2):250-255.

70. Scott IU. Early detection of choroidal neovascularization: a new paradigm in the management of AMD. Paper presented at the Annual Meeting of the American Academy of Ophthalmology. October 15-18, 2005; Chicago, IL.

71. Crossland M, Rubin G. The Amsler chart: absence of evidence is not evidence of absence. Br J Ophthalmol. 2007;91(3):391-393.

72. Loewenstein A, Malach R, Goldstein M, et al. Replacing the Amsler grid: a new method for monitoring patients with age-related macular degeneration. Ophthalmology. 2003;110(5):966-970.

73. Alster Y, Bressler NM, Bressler SB, et al; Preferential Hyperacuity Perimetry Research Group. Preferential Hyperacuity Perimeter (PreView PHP) for detecting choroidal neovascularization study. Ophthalmology. 2005;112(10):1758-1765.

74. Loewenstein A, Ferencz JR, Lang Y, et al. Toward earlier detection of choroidal neovascularization secondary to age-related macular degeneration: multicenter evaluation of a preferential hyperacuity perimeter designed as a home device. Retina. Jul-Aug 2010;30(7):1058-1064.

75. College of Optometrists. Framework for Optometric Referrals. London: College of Optometrists; March, 2010.
76. Muen WJ, Hewick SA. Quality of optometry referrals to neovascular age-related macular degeneration clinic: a prospective study. JRSM Short Rep. 2011;2(8):64.

77. Prasad S, Kamath GG, Jones K, Clearkin LG, Phillips RP. Effectiveness of optometrist screening for diabetic retinopathy using slit-lamp biomicroscopy. Eye (Lond). 2001;15(Pt 5):595-601.

78. Arbuthnot T. PEARS scheme in Wales: results of a practice self-audit. Optometry Today. November 4, 2005;22-24.

79. Lalwani GA, Rosenfeld PJ, Fung AE, et al. A variable-dosing regimen with intravitreal ranibizumab for neovascular age-related macular degeneration: year 2 of the PrONTO Study. Am J Ophthalmol. 2009;148(1):43-58. e1.

80. Manousaridis K, Manjunath V, Talks J. Information used to decide on retreatment of exudative age-related macular degeneration with anti-VEGF in clinical practice. Eur J Ophthalmol. 2013; 23(1):3

81. AMD Alliance International. Awareness of Age-Related Macular Degeneration and Associated Risk Factors: AMD Global Report 2005. Toronto: AMD Alliance International; 2005. Available from: http:// www.amdalliance.org/user_files/documents/Global_Report_Aug22. doc. Accessed October 26, 2012.

82. Noertjojo K, Maberley D, Bassett K, Courtright P. Awareness of eye diseases and risk factors: identifying needs for health education and promotion in Canada. Can J Ophthalmol. 2006;41(5):617-623.

83. Handa S, Woo JH, Wagle AM, Htoon HM, Au Eong KG. Awareness of blindness and other smoking-related diseases and its impact on motivation for smoking cessation in eye patients. Eye (Lond). 2011;25(9): 1170-1176.

84. Gorin SS, Heck JE. Meta-analysis of the efficacy of tobacco counseling by health care providers. Cancer Epidemiol Biomarkers Prev. 2004;13(12):2012-2022.

85. Thompson C, Harrison RA, Wilkinson SC, Scott-Samuel A, Hemmerdinger C, Kelly SP. Attitudes of community optometrists to smoking cessation: an untapped opportunity overlooked? Ophthalmic Physiol Opt. 2007;27(4):389-393.

86. Brûlé J, Abboud C, Deschambault E. Smoking cessation counselling practices among Québec optometrists: evaluating beliefs, practices, barriers and needs. Clin Exp Optom. 2012;95(6):599-605.

87. Kennedy RD, Spafford MM, Schultz AS, Iley MD, Zawada V. Smoking cessation referrals in optometric practice: a Canadian pilot study. Optom Vis Sci. 2011;88(6):766-771.

88. Gordon JS, Andrews JA, Lichtenstein E, Severson HH, Akers L, Williams C. Ophthalmologists' and optometrists' attitudes and behaviours regarding tobacco cessation intervention. Tob Control. 2002;11(1): $84-85$.

89. Spafford MM, Iley MD, Schultz AS, Kennedy RD. Tobacco dependence education in optometry: a Canadian pilot study assessing practices and opportunities. Optom Educ. 2010;36(1):38-44.

90. Centers for Medicare and Medicaid Services. 2011 Physician Quality Reporting System Measure Specifications Manual for Claims and Registry Reporting of Individual Measures. 2011. Available from: http://www.cms.gov/Medicare/Quality-Initiatives-Patient-AssessmentInstruments/PQRS/downloads/2011_PhysQualRptg_MeasureSpecificationsManual_033111.pdf. Accessed October 11, 2012.

91. Sheck LH, Field AP, McRobbie H, Wilson GA. Helping patients to quit smoking in the busy optometric practice. Clin Exp Optom. 2009;92(2):75-77.

92. US Department of Agriculture, US Department of Health and Human Services. Dietary Guidelines for Americans, 2010. 7th ed. Washington DC: US Government Printing Office; 2010.

93. [No authors listed]. What eye care patients should know about nutrition. Optometry. 2009;80(10):590-591.

94. Elliott JG, Williams NS. Nutrients in the battle against age-related eye diseases. Optometry. 2012;83(1):47-55.

95. Krishnadev N, Meleth AD, Chew EY. Nutritional supplements for age-related macular degeneration. Curr Opin Ophthalmol. 2010;21(3): 184-189. 
96. Raniga A, Elder MJ. Dietary supplement use in the prevention of agerelated macular degeneration progression. NZ Med J. 2009;122(1299): 32-38.

97. Anshel JR, Gerson JD, Capogna L, Richer SP, Shechtman DL. New paradigms in the understanding and management of ocular nutrition. Review of Optometry. Available at http://www.revoptom.com/supplement_toc/s/201/. Accessed 9 November, 2012.

98. Larson T, Coker J. A descriptive study of lutein and zeaxanthin in optometric practice. Optometry. 2009;80(10):579-586.

99. Glazer-Hockstein C, Dunaief JL. Could blue light-blocking lenses decrease the risk of age-related macular degeneration? Retina. 2006;26(1):1-4.

100. Mainster MA, Turner PL. Blue-blocking IOLs decrease photoreception without providing significant photoprotection. Surv Ophthalmol. 2010;55(3):272-289.

101. Roberts JE. Ultraviolet radiation as a risk factor for cataract and macular degeneration. Eye Contact Lens. 2011;37(4):246-249.

102. Information on nutrition and eye health. Optometry. 2009;80(10): 599-601.

103. Bureau of Labor Statistics. Optometrists. In: Occupational outlook handbook: healthcare [web page on the Internet]. 2012-2013 ed. Washington DC: Bureau of Labor Statistics; 2012. http://www.bls. gov/ooh/Healthcare/Optometrists.htm. Accessed August 6, 2012.
104. Resnikoff S, Felch W, Gauthier TM, Spivey B. The number of ophthalmologists in practice and training worldwide: a growing gap despite more than 200,000 practitioners. Br J Ophthalmol. 2012;96(6): 783-787.

105. National Statistics, National Health Service Health and Social Care Information Centre. General Ophthalmic Services: Workforce Statistics for England and Wales. Leeds: National Health Service Health and Social Care Information Centre; 2012. Available from: http:// www.ic.nhs.uk/webfiles/publications/007_Primary_Care/Eye_care/ General_Ophthalmic_Services_Wkforce_31DEC2011/GOS_Work force_Stats_Eng_Wal_31Dec11_Report.pdf. Accessed August 8, 2012.

106. Australian Institute of Health and Welfare. Eye Health Labour Force in Australia. Canberra: Australian Institute of Health and Welfare; 2009.

107. Canadian Institute for Health Information. Canada's Health Care Providers, 2000 to 2009: A Reference Guide. Ottawa: Canadian Institute for Health Information; 2011.
Clinical Optometry

\section{Publish your work in this journal}

Clinical Optometry is an international, peer-reviewed, open access journal publishing original research, basic science, clinical and epidemiological studies, reviews and evaluations on clinical optometry. All aspects of patient care are addressed within the journal as well as the practice of optometry including economic and business analyses. Basic and clinical

\section{Dovepress}

research papers are published that cover all aspects of optics, refraction and its application to the theory and practice of optometry. The manuscript management system is completely online and includes a very quick and fair peer-review system, which is all easy to use. Visit http://www.dovepress. com/testimonials.php to read real quotes from published authors. 